Dom. Cien., ISSN: 2477-8818

Vol. 5, núm.1., ene, 2019, pp. 560-588

Factores de riesgo que inciden con la presencia de herpes genital en la mujer

\title{
Factores de riesgo que inciden con la presencia de herpes genital en la mujer
}

\author{
Climate change and its incidence in tropical diseases
}

\section{Mudança climática e sua incidência em doenças tropicais}

\author{
Jenny V. Magallanes-Sánchez ${ }^{\mathrm{I}}$ \\ lavivi01ms@homail.com \\ Leonela L. Ponce-Lino ${ }^{\text {II }}$ \\ leytopl@hotmail.com \\ Yojana M. Vélez-Valencia ${ }^{\text {III }}$ \\ ymvelez@utm.edu.ec \\ Rosa M. Navia-González IV \\ rnavia@utm.edu.ec
María L. Cedeño-García V mlcedeno@utm.edu.ec \\ María V. Zambrano-Intriago VI \\ mvzambrano@utm.edu.ec
}

Recibido: 27 de noviembre de 2018 * Corregido: 18 de diciembre de 2018 * Aceptado: 20 de diciembre de 2018

\footnotetext{
Obstetriz; Ministerio Salud Pública, Hospital de Especialidades Portoviejo, Ecuador.

II. Licenciada en Enfermería; Enfermera de Cuidados Directo en el IESS Jipijapa; Cursa la especialidad de Orientación Familiar Integral, Manabí, Ecuador.

III. Magister en Gerencia en Salud para el Desarrollo Local; Hospital General Chone; Universidad Técnica de Manabí, Portoviejo, Manabí, Ecuador.

IV. Magister en Gerencia en Salud para el Desarrollo Local; Hospital General Chone; Universidad Técnica de Manabí, Portoviejo, Manabí, Ecuador.

V. Magister en Gerencia en Salud para el Desarrollo Local; Hospital General Chone; Universidad Técnica de Manabí, Portoviejo, Manabí, Ecuador.

VI. Magister en Gerencia en Salud para el Desarrollo Local; Hospital General Chone; Universidad Técnica de Manabí, Portoviejo, Manabí, Ecuador.
} 


\section{Resumen}

Las evidencias halladas en investigaciones nuevas indican que el herpes genital es un importante problema de salud, sin embargo, por las limitaciones previstas en estos mismos estudios, no se llega a explicar el impacto que, aspecto psicosocial, genera este tipo de enfermedad. Es básicamente por esa razón que el presente trabajo de investigación se enfocó en realizar una revisión bibliográfica encaminada a la epidemiología, tratamiento e impacto que genera la enfermedad del herpes genital en la mujer. El trabajo está enmarcado en una investigación documental, que inició con la búsqueda de información en libros, revistas especializadas, internet, folletos, tesis, datos estadísticos, entre otras fuentes; y mediante la observación, orden, clasificación, resumen y análisis del material bibliográfico seleccionado en base a criterios de temática, idioma español e inglés y relevancia, se pudo llevar a cabo un resumen deductivo, que concluyó con la afirmación de que, el herpes genital es la enfermedad crónica de transmisión sexual de mayor incidencia en el mundo; sin embargo, en nuestro país no existe el fácil acceso a información especializada y a estadísticas que expongan la magnitud de este gran problema.

Palabras claves: Herpes Genital; Impacto Psicosocial; Herpes Simplex; Síndrome de Inmunodeficiencia Adquirida. 


\begin{abstract}
The evidence found in new research indicates that genital herpes is an important health problem, however, due to the limitations provided in these studies, the impact of this type of disease, psychosocial aspect, can not be explained. It is basically for this reason that the present research work focused on carrying out a bibliographic review aimed at the epidemiology, treatment and impact generated by the genital herpes disease in women. The work is framed in a documentary research, which began with the search of information in books, specialized magazines, internet, brochures, theses, statistical data, among other sources; and through the observation, order, classification, summary and analysis of the selected bibliographic material based on thematic criteria, Spanish and English language and relevance, a deductive summary could be carried out, which concluded with the affirmation that genital herpes it is the most common chronic sexually transmitted disease in the world; However, in our country there is no easy access to specialized information and statistics that expose the magnitude of this great problem.
\end{abstract}

Key words: Genital Herpes, Psychological and Social Impact; Herpes Simplex; Aqcuired Inmune Defficiency Virus. 


\section{Resumo}

As evidências encontradas em novas pesquisas indicam que o herpes genital é um importante problema de saúde, entretanto, devido às limitações fornecidas nesses estudos, o impacto desse tipo de doença, aspecto psicossocial, não pode ser explicado. É basicamente por este motivo que o presente trabalho de pesquisa se concentrou na realização de uma revisão bibliográfica direcionada à epidemiologia, tratamento e impacto gerados pela herpes genital em mulheres. O trabalho é enquadrado em uma pesquisa documental, que começou com a busca de informações em livros, revistas especializadas, internet, folhetos, teses, dados estatísticos, entre outras fontes; e através da observação, ordem, classificação, resumo e análise do material bibliográfico selecionado com base em critérios temáticos, língua e relevância em espanhol e inglês, pode-se realizar um resumo dedutivo, que concluiu com a afirmação de que o herpes genital é o mais comum doença sexualmente transmissível crônica no mundo; No entanto, em nosso país, não há acesso fácil a informações e estatísticas especializadas que exponham a magnitude desse grande problema.

Palavras-Chave: Herpes Genital; Impacto Psicológico e Social; Herpes simples; Aqcuired Inmune Defficiency Virus. 


\section{Introducción.}

El propósito de este artículo es llamar la atención de los profesionales sobre las características poco conocidas relacionados con los recientes cambios en la epidemiología, el diagnóstico y manejo terapéutico de las infecciones causadas por virus del herpes simple. Olmos (2010) indicó que:

A nivel mundial, a la falta de atención que se les da a estas enfermedades, se le ha llamado "la cultura del silencio", a pesar de sus obvios efectos negativos y de que son prevenibles, diagnosticables y tratables. Esta "cultura del silencio" creada alrededor de las enfermedades de transmisión sexual (ETS) entre las mujeres, es uno de los factores más importantes a superar para su mejor prevención y tratamiento. (Abad, M.; 2014; p. 10)

La edad fértil de la mujer inicia con la menarquia y culmina en la menopausia, la misma que generalmente comprende desde los 15 hasta los 49 años de edad y es durante esta etapa en donde las mujeres están en riesgo de adquirir muchas morbilidades, entre las que se encuentran las ETS.

El aumento tan notable de las ETS, no solamente se deben a factores irreversibles, como el incremento natural de la población, o la mayor duración de la vida sexual, o las mejores técnicas de diagnóstico, sino también a factores socioeconómicos y culturales, como el mayor poder adquisitivo, la emigración y el turismo, la liberación económica y sexual de la mujer que la cultura ha permitido, la tolerancia de los diferentes hábitos sexuales, los escasos modelos de referencia y sobre todo a factores médico-sanitarios, como escasos centros especializados, escasa información médica, escasa coordinación interdisciplinaria, escasa formación de personal sanitario, diagnósticos y tratamientos incorrectos, recidivas por exceso de confianza y automedicación. 
No debemos olvidar que entre los factores culturales que pueden aumentar la difusión de las ETS podría incluirse los escasos contactos familiares, el bajo nivel de instrucción, creencias sobre sexualidad, la mala práctica de higiene individual, los aspectos socio-demográficos, el no uso de métodos anticonceptivos de barrera 10 y creencias religiosas, la influencia negativa de los medios de comunicación en las adolescentes, la pobreza y la promiscuidad. (Abad, M.; 2014; p. 8-9)

Se consideran estas enfermedades como una verdadera epidemia de nuestra época. Se producen en el mundo 250.000.000 de casos nuevos cada año, en las Américas se estima una cifra de alrededor de 50.000.000 anualmente. Las más frecuentes en la actualidad son las siguientes: Vaginosis Bacteriana, Herpes genital, infección por Clamidias, Tricomoniasis, Candidiasis, Infecciones por Virus Papiloma Humanos, Hepatitis B, Sífilis y el SIDA. ((Berdasquera, D., Fariñas, A., \& Ramos, I.; 2001)

\section{Materiales y Métodos.}

Para poder alcanzar el objetivo particular de esta investigación, se hizo indispensable iniciar una búsqueda de información, mediante la utilización de diferentes materiales, métodos, técnicas e instrumentos, entre ellos: libros, revistas especializadas, internet, folletos, tesis, datos estadísticos, entre otras fuentes, que facilitaron el desarrollo de una investigación documental en la que mediante la observación, orden, clasificación, resumen y análisis del material bibliográfico seleccionado en base a criterios de temática, idioma español e inglés y relevancia, se pudo llevar a cabo un resumen deductivo, que permitió fundamentar científicamente las bases teóricas, diferentes ideas y criterios del equipo investigador, constituyendo y compartiendo en definitiva, un solo criterio respecto al tema y problemática planteada, el cual se ha expuesto entre los resultados y conclusiones obtenidas.

\footnotetext{
565 Vol. 5, núm. 1, enero 2019, pp. 560-588 Jenny V. Magallanes-Sánchez; Leonela L. Ponce-Lino; Yojana M. Vélez-Valencia; Rosa M. NaviaGonzález; María L. Cedeño-García; María V. Zambrano-Intriago
} 


\section{Resultados.}

Es importante iniciar aclarando que, de conformidad a la Organización Mundial de la Salud:

La infección por el virus del herpes simple, denominada por lo general herpes, puede deberse al virus del herpes simple de tipo 1 (VHS-1) o al virus del herpes simple de tipo 2 (VHS-2). El VHS-1 se transmite principalmente por contacto de boca a boca y causa infecciones en la boca o a su alrededor (herpes labial). El VHS-2 se transmite casi exclusivamente por vía sexual y provoca infecciones en la zona genital o anal (herpes genital). Sin embargo, el VHS-1 también puede transmitirse a la zona genital por contacto bucogenital y provocar herpes genital.

La infección por VHS-1 es muy contagiosa, frecuente y endémica en todo el mundo. Se adquiere mayoritariamente durante la infancia y dura toda la vida. La gran mayoría de las infecciones por VHS-1 son herpes labiales (infecciones en la boca o a su alrededor, por lo que se denomina en ocasiones herpes bucal, labial o bucofacial), si bien algunas son herpes genitales (infecciones en la zona genital o anal) (OMS, 2017)

El herpes genital es una infección frecuente de transmisión sexual causada por el virus del herpes simple. El contacto sexual es la principal vía de propagación del virus. Después de la infección inicial, el virus permanece inactivo en el cuerpo y puede reactivarse varias veces al año.

El herpes genital puede provocar dolor, picazón y llagas en la zona genital. Pero es posible que no tengas ningún signo ni síntoma. Si estás infectado, puedes contagiar, aun cuando no tengas llagas visibles.

El herpes genital no tiene cura, pero los medicamentos pueden aliviar los síntomas y reducir 
el riesgo de infectar a otras personas. Los preservativos también pueden ayudar a prevenir la propagación de una infección por herpes genital.

La mayoría de las personas infectadas con el virus del herpes simple no sabe que tiene la infección porque no tiene signos ni síntomas o porque estos son muy leves.

Cuando se manifiestan, los síntomas aparecen entre 2 y 12 días después de la exposición al virus. Si tienes síntomas de herpes genital, pueden ser:

- Dolor o picazón. Puedes sentir dolor y dolor con la palpación en la zona genital hasta que desaparezca la infección.

- Protuberancias rojas pequeñas o ampollas blancas diminutas. Pueden aparecer unos días o unas semanas después de la infección.

- Úlceras. Se pueden formar cuando las ampollas se rompen y supuran o sangran. Las úlceras pueden provocar dolor al orinar.

- Costras. Se forman costras en la piel a medida que las úlceras se curan.

Durante un brote inicial, es posible que tengas signos y síntomas similares a los de la influenza, como ganglios linfáticos inflamados en la ingle, dolor de cabeza, dolores musculares y fiebre. (Mayo Clinic, 2017)

Las áreas de mayor prevalencia son África y América. En Europa Oriental, la prevalencia es más baja que en Europa occidental. El área de menor prevalencia es Asia. Los países de mayor incidencia son los de África Subsahariana, con $80 \%$ de personas infectadas menores de 35 años. Un estudio de cohorte realizado en Akaki, Etiopía, muestra que la mitad de la población urbana es positiva a anticuerpos. Otros estudios denotan una prevalencia de $10 \%$ a $60 \%$ de la población

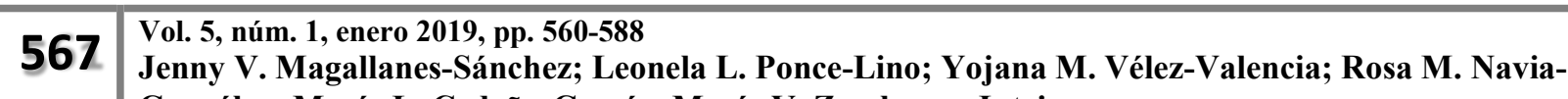
González; María L. Cedeño-García; María V. Zambrano-Intriago
} 
infectada en países desarrollados. Por otra parte, Gottlieb declara que el Herpes Genital constituye la enfermedad de transmisión sexual de mayor prevalencia (22\%) en los Estados Unidos de América. Su incidencia es de 0,8 a 5,1 de personas por año. Sin embargo, la mayoría de las personas son asintomáticas.

Existen diferencias de género en la prevalencia de anticuerpos VHS2; éste es mayor en las mujeres que en los hombres, siendo la frecuencia de infección mayor entre las edades de 20 a 30 años. Dentro de los factores que pueden influir en la adquisición de la enfermedad están: etnicidad, estado civil, lugar de residencia, antecedentes de Infecciones de Transmisión Sexual (ITS), nivel educacional, promiscuidad, inmunodeficiencia y abuso de drogas. Por otro lado, estudios en homosexuales han demostrado seroprevalencia de 34\%. Además, muchos de los países, al igual que en nuestro país, no llevan estadísticas de la enfermedad.

El tratamiento del Herpes Genital está encaminado a disminuir los síntomas, promover la epitelización, reducir los niveles de virus para disminuir la transmisibilidad y prevenir futuras recurrencias. Los nucleósidos análogos son los medicamentos de primera línea para suprimir la infección por Herpes. Dentro de los nucleósidos análogos se encuentran el Acyclovir, Famciclovir y el Valacyclovir. Otros medicamentos como el Foscernet, Cidofovir y Trifluridine pueden ser apropiados en situaciones clínicas específicas. Los nucleósidos análogos inhiben la replicación viral a través de una purina sintética nombrada (9-2-hydroxyethoxymethyl). El Aciclovir es convertido en monofosfato por la Timidina Kinasa del HSV. Las Kinasas celulares procesan el monofosfato a Aciclovir trisfosfato que es el mecanismo activo del medicamento. La fosforilización del Aciclovir solo ocurre en células infectadas. Estudios in vitro indican una concentración de trisfosfato en células infectadas de 200 a 1000 más que en células no infectadas. Por consiguiente, el DNA 
polimerasa del virus tiene mayor predilección por el trisfosfato del Aciclovir que por el DNA polimerasa de la célula. Esto conlleva una inhibición del DNA viral.

El tratamiento diariamente supresivo con estas drogas puede disminuir los niveles de virus y puede limitar las recurrencias significativamente. La terapia supresiva debe ser indicada fundamentalmente desde el inicio hasta los 9 meses después de la infección, ya que en los meses iniciales es donde se reportan mayores descargas virales. Sin embargo, $80 \%$ de la terapia es indicada en presencia de síntomas. (Hernández, A.; 2008)

\section{Cuadro clínico}

Las infecciones por herpes genital pueden clasificarse como primoinfección o como recurrencia. El primer episodio, infección primaria, ocurre en individuos sin exposición previa. También puede presentarse como infección no primaria en pacientes con antecedente de infección por VHS 1 que luego adquieren la infección por el subtipo 2, o viceversa. Mientras que la recurrencia es aquella infección que se da en pacientes con exposición previa y que desarrollan reactivación de infección.

Tanto la primoinfección como las recurrencias pueden ser subclínicas y presentar síntomas de diferente intensidad. Los síntomas sistémicos como fiebre, cefalea, mialgias, artralgias, astenia, entre otros, son más frecuentes en la primoinfección. Los síntomas locales como lesiones vesiculosas y ampollas se presentan con mayor frecuencia en las recurrencias. Estas lesiones se rompen y producen úlceras dolorosas localizadas en genitales externos, con posterior formación de costras. En vagina, cérvix uterino o uretra, las úlceras se rompen y el tejido permanece cruento hasta su reepitelización. Otros síntomas asociados son disuria, leucorrea, uretrorrea y adenomegalias 
inguinales. Los síntomas en la infección primaria son más severos y tienen una duración aproximada de 2 a 3 semanas. Las recurrencias tienen una duración de 2 a 10 días, con una frecuencia promedio de cuatro episodios por año. En las recurrencias las lesiones genitales son menos severas y pueden llegar a pasar desapercibidas. Dentro de las complicaciones descritas se encuentra la radiculopatía sacra del sistema nervioso autónomo, retención urinaria, enfermedad diseminada (neumonitis, hepatitis, meningitis), cronicidad de la infección mediante la recurrencia y en las pacientes gestantes se pueden presentar transmisión vertical al feto con resultados perinatales adversos. (Delgado, Caicedo, Manrique, \& Cañón, 2014, p. 204)

Herpes genital y otros problemas de salud

En algunas personas cuyo sistema inmunitario no funciona apropiadamente, los episodios de herpes genital pueden durar más tiempo y ser más graves.

Si una mujer tiene su primer episodio de herpes genital mientras está embarazada, puede transmitirle el virus a su futuro hijo y puede tener un parto prematuro. La mitad de los niños infectados por herpes mueren o sufren lesión en su sistema nervioso. Un recién nacido con herpes puede desarrollar complicaciones graves que pueden afectar a su cerebro, piel u ojos. Estos niños deben ser tratados inmediatamente con aciclovir para que aumenten sus posibilidades de estar sanos. El control estricto por parte del médico es esencial es estos casos Si una mujer embarazada tiene un brote que no es el primer episodio de la infección, el riesgo de infección del recién nacido durante el parto es muy bajo. Si una mujer tiene un brote durante el parto y existen lesiones en el canal del parto o alrededores, el médico practicará una cesárea para proteger al niño. Sin embargo, la mayoría de mujeres con herpes genital no tienen signos de infección activa por el virus y tendrán un parto normal. 
El herpes genital, al igual que otras enfermedades genitales que producen úlceras, aumenta el riesgo de una persona de infectarse por el virus de la inmunodeficiencia humana (VIH), el virus que causa el síndrome de inmunodeficiencia adquirida (SIDA). Asimismo, antes de los actuales mejores tratamientos del SIDA, las personas con el VIH tienen brotes de herpes más severos, a causa de la menor protección que les proporciona su sistema inmunitario afectado por el VIH. Este hecho puede ayudar a transmitir más fácilmente tanto el VHS como el VIH a otras personas. (Giménez, S.; 2014)

\section{Prevención}

Si tienes síntomas precoces de un brote por herpes o úlceras visibles, no debes mantener relaciones sexuales o practicar sexo oral hasta que hayan desaparecido los síntomas y se hayan curado las úlceras. Entre los brotes, deberías usar condones durante las relaciones sexuales, ya que proporcionan cierta protección frente al virus. (Giménez, S.; 2014)

\section{Enfermedades De Transmisión Sexual (ETS)}

Las Enfermedades de Transmisión Sexual conllevan muchos años con lo que poco a poco se han ido apareciendo distintas enfermedades que son transmitidas por el coito, y con el paso de los años, médicos y científicos han contribuido a la ciencia de la salud encontrando su adecuado tratamiento. (Abad, M.; 2014: p. 14)

\section{Concepto de Enfermedades de Transmisión Sexual}

"Las enfermedades de transmisión sexual son infecciones que se propagan principalmente de persona a persona a través de contactos sexuales. Hay más de 30 bacterias, virus y parásitos transmisibles por vía sexual. Algunos, también se pueden transmitir de la madre al hijo durante el

\footnotetext{
\begin{tabular}{l|l}
571 & Vol. 5, núm. 1, enero 2019, pp. 560-588 \\
Jenny V. Magallanes-Sánchez; Leonela L. Ponce-Lino; Yojana M. Vélez-Valencia; Rosa M. Navia-
\end{tabular} González; María L. Cedeño-García; María V. Zambrano-Intriago
} 
embarazo y el parto, así como a través de las transfusiones sanguíneas y los trasplantes de tejido (OMS, 2011).

Las armas más importantes contra las ETS son la prevención, tomando las medidas oportunas por medio del uso del condón y la higiene adecuada, elementos imprescindibles para una sexualidad responsable reduciendo considerablemente el riesgo de contagio de estas enfermedades. (Abad, M.; 2014: p. 14)

\section{Dinámica de Transmisión}

Como menciona la estrategia mundial de prevención y control de las infecciones de transmisión sexual 2006-2015 (OMS, 2007) en la población, la distribución de las infecciones no es estática, con el tiempo, las epidemias siguen distintas fases que se caracterizan por sus diferentes pautas de distribución y transmisión de los agentes patógenos dentro de las subpoblaciones y entre ellas. Por lo general, los agentes patógenos de transmisión sexual se transmiten más probablemente entre personas de alto riesgo, frecuentemente infectadas, que cambian a menudo de pareja sexual y de estas personas a otras. A medida que avanza la epidemia, los agentes patógenos se propagan a poblaciones. Las que son más vulnerables por sus condiciones sociales o económicas y culturales.

En cuanto a la capacidad de infecciosidad de algunos agentes patógenos (por ejemplo, Haemophilus ducreyi) son muy infecciosos pero el periodo durante el cual la persona infectada puede contagiar la enfermedad es breve, mientras que otros, 15 como el VIH y el virus del Herpes Simple de tipo 2 tienen una infecciosidad relativamente baja pero el periodo de contagio es largo. La Neisseria Gonorrhoeae, Chlamydia trachomatis y Treponema pallidum, tienen infecciosidad y duración intermedias. Así la epidemia de una infección de transmisión sexual será distinta según el

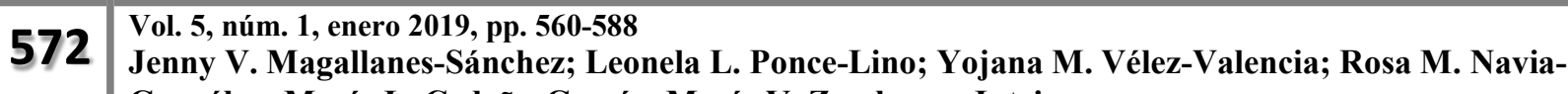
González; María L. Cedeño-García; María V. Zambrano-Intriago
} 
tipo de interacción entre la población y el agente patógeno. (OMS, 2007) citada por (Abad, M.; 2014: p. 14)

\section{Promoción del Comportamiento Sexual Saludable}

Una excelente forma de prevenir la propagación de las enfermedades de transmisión sexual comienza con la prevención, mediante el suministro de información exacta y explícita sobre prácticas sexuales menos arriesgadas, por ejemplo, sobre la utilización correcta y sistemática de preservativos masculinos y femeninos, así como sobre la abstinencia, el retraso del inicio de la vida sexual, la monogamia o la reducción del número de parejas sexuales. (Abad, M.; 2014: p. 16)

Además de las intervenciones de prevención, devén haber servicios de salud disponibles para dispensar un tratamiento temprano y eficaz. La educación sobre salud en relación con las infecciones de transmisión sexual y asesoramiento de las personas infectadas y no infectadas, incluidos el asesoramiento y las pruebas voluntarias y confidenciales para el VIH, deben formar parte integral de todo servicio de salud relacionado con esas infecciones, ya que el proceso genera motivación para cambiar los comportamientos sexuales en las personas. (OMS, 2007) citada por (Abad, M.; 2014: p. 16)

Herpes genital y síndrome de inmuno deficiencia adquirida (SIDA)

La sinergia entre el Herpes Genital y el SIDA ha sido demostrada en numerosos estudios epidemiológicos y clínicos. La infección por virus de inmunodeficiencia adquirida (HIV) exacerba la frecuencia del Herpes Simple; más de $80 \%$ de los pacientes con HIV padecen Herpes Simple. Además, el Herpes Simple aumenta el riesgo de adquirir HIV. La revisión de 18 estudios longitudinales reporta que previa a la infección con Herpes Simple había la posibilidad de contraer

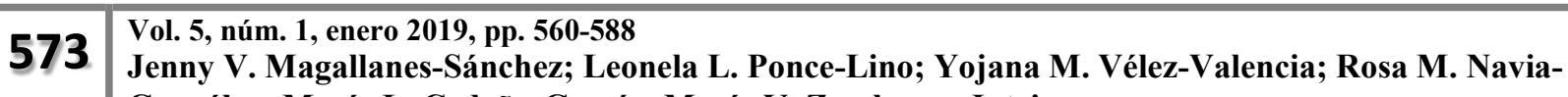
González; María L. Cedeño-García; María V. Zambrano-Intriago
} 
el HIV en 3,1 para mujeres; 2,7 entre hombres heterosexuales y 1,7 entre hombres que practican sexo con hombres. De acuerdo con (Roest, W.; 2006), el HSV-2 fue el factor de riesgo más importante asociado con el HIV en 1.080 parejas estudiadas en 4 sitios de África. Estudios in vitro demuestran que en las lesiones por Herpes Genital existen una gran cantidad de CD4+T; estas células son las predilectas del HIV, por lo que aumenta el riesgo de infección. Por otro lado, en caso del que paciente sea portador de HSV y HIV, las células T están cargadas de HIV, por lo que aumenta el riesgo de contagio a pacientes sanos. Adicionalmente, los productos del HSV influyen en las proteínas HIV-1 ICPO, ICP4 y ICP27; estas proteínas aumentan la transcripción del HIV. Incrementan in vitro la estabilización post-transcripcional del RNA del HIV. Posiblemente, el HSV induce la expresión del HIV mediante el gen activador, llamado factor nuclear KB (NF-KB). La sinergia entre el virus del Herpes Simple y el HIV-1 constituye en opinión del autor un importante problema de salud para nuestro país y para el mundo. Debido a que podrían aumentar la incidencia del SIDA a partir de casos infectados con Herpes Simple. (Hernández, A.; 2008)

\section{Uso de preservativo para la prevención}

A pesar de que el condón ha sido utilizado durante mucho tiempo, el puritanismo característico de la sociedad occidental lo ha mantenido en la obscuridad y como un tema intocable en sociedad. Sin embargo, con la aparición de la epidemia del síndrome de inmunodeficiencia adquirida, el condón se ha convertido en uno de los principales métodos para prevenir la transmisión sexual del virus de la inmunodeficiencia humana (VIH).

Las otras medidas para prevenir las enfermedades sexualmente transmisibles son: la abstinencia sexual; tener relaciones sexuales sólo con una pareja y además que ésta no padezca alguna enfermedad de transmisión sexual y practicar el "sexo seguro".

\footnotetext{
574 Vol. 5, núm. 1, enero 2019, pp. 560-588 
El preservativo masculino de látex es la tecnología más eficaz disponible para reducir la transmisión sexual del VIH y de otros agentes patógenos de transmisión sexual. El preservativo masculino, junto con el femenino, constituyen un componente clave de las estrategias integrales de prevención, y ambos deben ponerse de manera fácil y sistemática a disposición de todos los que los necesiten para reducir los riesgos de la exposición sexual a agentes patógenos, en particular el VIH (OMS, 2007) citada en (Abad, M.; 2014: p. 17)

\section{Acceso a los medicamentos y a una tecnología apropiada}

La disponibilidad regular de medicamentos apropiados es indispensable para el control de las infecciones de transmisión sexual. Un tratamiento rápido y eficaz permite romper la cadena de transmisión y prevenir la aparición de complicaciones y secuelas a largo plazo. Un medicamento apropiado para el tratamiento de una infección de transmisión sexual es un medicamento de gran eficacia y de una toxicidad aceptable, que probablemente no genere resistencia microbiana o la genere a largo plazo, que se administre por vía oral, preferiblemente en dosis única y que no esté contraindicado en embarazadas o mujeres lactantes.

\section{Vacunas}

Dado que la inmunización de las poblaciones expuestas es, en general, un método sumamente eficaz para combatir las enfermedades infecciosas, las vacunas serían un importante complemento del arsenal de tecnologías de prevención ya existentes. Actualmente, la vacuna contra la Hepatitis B es la única vacuna eficaz que se dispone contra un agente patógeno transmitido por vía sexual. El desarrollo de nuevas vacunas contra la infección por el Virus del Papiloma Humano (VPH) podría evitar la muerte prematura de aproximadamente 240000 mujeres por cáncer

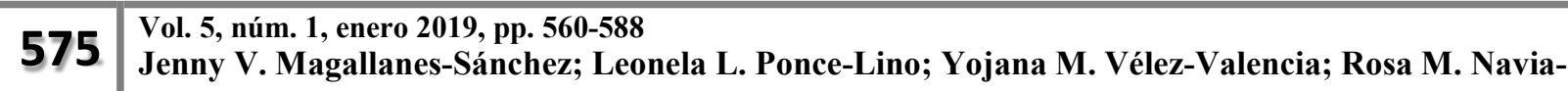
González; María L. Cedeño-García; María V. Zambrano-Intriago
} 
cervicouterino cada año en los entornos con pocos recursos. (OMS, 2007) citado en (Abad, M.; 2014: p. 18)

\section{Enfermedades bacterianas}

\section{Clamidiasis (Etiología)}

El agente causal de esta enfermedad es la Clamidia Trachomatis bacteria Gramnegativa carente de mecanismos para producir energía metabólica y no puede sintetizar trifosfato de adenosina (ATP), es un patógeno especifico humano cuyos cuerpos elementales se adhieren al epitelio columnar o transicional, se incorpora por pinocitosis permaneciendo dentro de un fagosoma que las protege de las defensas del huésped ahí se convierten en cuerpos reticulares que se multiplican (durante 24 a 48 horas ) invadiendo y rompiendo la célula y liberando partículas infectantes en el espacio extracelular. (Jawetz, M.; 2008) citado en (Abad, M.; 2014: p. 20)

\section{Manifestaciones clínicas}

Según Morgan y Colds en (Morgan, M.; 2006) con frecuencia es asintomática 75\%. Y en los casos sintomáticos la uretritis se caracteriza por disuria y polaquiuria; la endocervicitis se asocia con leucorrea mucupulenta y sangrado poscoital, cuello congestivo, puede haber inflamación de las glándulas de Skene y Bartholinin. Entre las complicaciones más frecuentes de esta infección están la Enfermedad Inflamatoria Pélvica por infección ascendente, puede ocurrir reinfecciones o infecciones 21 crónicas y son características las graves secuelas originadas por la respuesta hiperinmunitaria que acelera el daño tisular. (Morgan, M.; 2006) En sujetos con predisposición genética se puede producir el síndrome de Reiter (artritis no bacteriana, asociada a uretritis o cervicitis, conjuntivitis y lesiones mucocutaneas), la presencia de esta afección durante la gestación

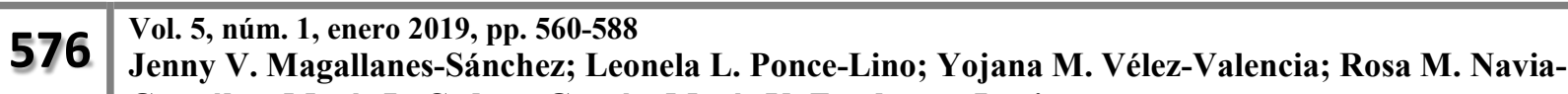
González; María L. Cedeño-García; María V. Zambrano-Intriago
} 
se asocia con abortos, retraso del crecimiento intrauterino y prematuridad. Si llega afectar al neonato hay afectación conjuntival y nasofaríngea que puede progresar a neumonía. (Usandizaga, J. \& Pérez, P.; s.f.) citado en (Abad, M.; 2014: p. 20-21)

\section{Diagnóstico}

A partir de muestras de uretra o cérvix para realizar un cultivo celular, para su diagnóstico se requiere que la muestra tenga material celular, No siendo suficiente el exudado. La presencia de antígenos se determina por la técnica de anticuerpos monoclonales con inmunofluorescencia directa, pero la técnica de inmunofluorescencia enzimáticas (ELISA) perece ser útil. Las técnicas ADN que utiliza la PCR son de mayor sensibilidad y especificidad. Las pruebas serológicas, la fijación de complemento se usan para el linfogranuloma. (Jawetz, M.; 2008) citado en (Abad, M.; 2014: p. 21)

\section{Tratamiento}

Se utiliza las antimicrobianos como: (Morgan, M.; 2006) Doxiciclina 100mg por vía oral cada 12 horas por 7 días. Azitromicina 1g por vía oral. Ofloxacina 300mg por vía oral cada 12 horas por 7 días. Eritromicina base 500mg vía oral cada 6 horas por 7 días. Levofloxacina 500mg por vía oral por 7 días. (Abad, M.; 2014: p. 21)

\section{Gonorrea}

Siguiendo el trabajo de Abad (2014), se sabe que se refiere a:

Infección de Transmisión Sexual causada por la bacteria Neisseria Gonorrhoeae un diplococo Gramnegativo de tamaño que fluctúa entre 0,6 y $1 \mu \mathrm{m}$ de diámetro, este microorganismo tiene la capacidad de cambiar las estructuras de superficie para evitar las defensas del huésped, entre

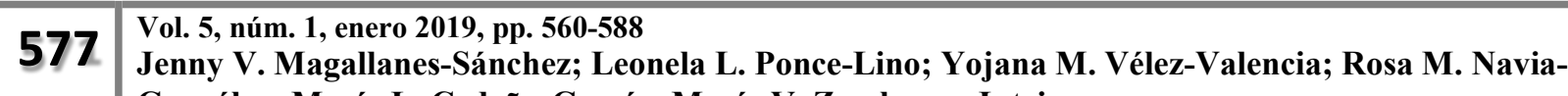
González; María L. Cedeño-García; María V. Zambrano-Intriago
} 
estas estructuras están los pili, los que incrementa la capacidad de adhesión a las células, la proteína Rmp la misma que se asocia a la Por en la formación de los poros sobre la superficie celular, también contienen en lipooligosacáridos los mismos que tienen una estructura similar a los glucoesfingolipidos de las membranas de las células humanas lo que ayuda al gonococo a evadir el reconocimiento inmunitario ya que la toxicidad de las infecciones gonocócicas se debe principalmente a los efectos endotóxicos de las lipooligosacáridos, además que estas bacterias tienen predilección por el epitelio columnar y de transición. (Jawetz, M.; 2008) en (Abad, M.; 2014: p. 2122)

Usandizaga, J. \& Pérez, P. (s.f.) (referidos por Abad, M.; 2014) aseguran que:

En la mujer puede causar cervicitis, uretritis, enfermedad inflamatoria pélvica. En los varones causa uretritis, prostatitis y epididimitis en ambos sexos es capaz de desarrollar secuelas sistémicas tardías. La gonorrea es una enfermedad especialmente contagiosa, se contagia a través del acto sexual. (p. 22)

De la misma manera se refieren a Morgan (2006) en cuanto a los factores de riesgo para la transmisión de este microorganismo patógeno, que son:

- Comienzo precoz de las relaciones sexuales.

- Múltiples parejas sexuales.

- Falta de uso de anticonceptivos de barrera.

\section{Manifestaciones clínicas}

Después de la exposición los síntomas se suelen manifestar 5 días después incluso pueden 
presentarse hasta los 30 días, las manifestaciones más frecuentes en la mujer son las de cervicitis gonocócica este microorganismo infecta especialmente al epitelio cilíndrico del orificio cervical e incluso en ocasiones afecta a las glándulas de Bartholin y Skene. Estos síntomas menores comprenden secreción mucopurulenta escasa que proviene del cuello uterino inflamado, disuria acompañada de uretritis gonocócica, otra manifestación de esta enfermedad es la vaginitis gonocócica donde, además, a la exploración física la mucosa vaginal se encuentra eritematosa y edematosa acompañada de la secreción purulenta, también puede haber erosión inflamatoria del cuello uterino u absceso de los quistes de Naboth. La infección gonocócica puede extenderse a los tejidos profundos para producir dispareunía, dolor hipogástrico o dolor lumbar. (Usandizaga, J. \& Pérez, P.; s.f.) Debido a que la anatomía femenina permite la propagación del exudado cervical al recto esto llega a producir Gonorrea anorrectal la que conlleva una proctitis aguda la que se manifiesta con dolor o prurito anorrectal, tenesmo, secreción rectal purulenta y hemorragia rectal. (FAUCI, Braunwald, \& Kasper, 2012) citados por (Abad, M.; 2014: p. 23)

Es importante mencionar que la Gonorrea puede provocar infecciones en otros sitios como: artritis gonocócica, septicemia, peri hepatitis, coriamnionitis o endometritis, endocarditis, gonorrea ocular. (Morgan, M.; 2006) (Abad, M.; 2014: p. 23)

\section{Diagnóstico}

El diagnóstico se basa en la identificación de N. Gonorrhoeae por alguno de los varios métodos: (Jawetz, M.; 2008)

Muestras: para cultivos y frotis se recolectan pues y secreciones de uretra, cérvix, recto, conjuntivas, faringe o liquido sinovial, en las enfermedades sistémica se requiere hemocultivo, pero 
es importante contar con un sistema especial de cultivo porque el gonococo es susceptible al sulfonato de polianetol, presenté en los medios estándar para hemocultivo.

\section{Frotis}

- Tinción de Gram: revela diplococo dentro de los piocitos, los frotis que se obtiene de exudado uretral de varón tienen una especificidad de 99\%, sensibilidad de $90 \%$ los frotis del exudado endocervical, la sensibilidad baja al 50\% y la especificidad al 95\%.

- Cultivo en medio de Thayer Martín modificado: se incuba en un medio q tiene 5\% de $\mathrm{CO} 2$ a $37^{\circ} \mathrm{C}$, con antimicrobianos para evitar el crecimiento de contaminantes, los microorganismos se identifican por su aspecto en el frotis con 24 tinción de Gram por su positividad a la oxidasa y mediante conglutinación, tinción inunofluorecencia.

- Prueba de amplificación de ácidos nucleicos: esta prueba es bastante específica y sensible en poblaciones de alto riesgo además que tiene la ventaja es que ofrece mejores resultados por su rápida detección y la capacidad de utilizar orina como fuente de obtención del patógeno. La desventaja es que debido a la reacción cruzada con otras especies de Neisseria está disminuye de especificidad.

(Abad, M.; 2014; p. 23-24)

\section{Tratamiento}

Las recomendaciones terapéuticas para la gonorrea genital baja no complicada son: Ceftriaxona 250mg IM en dosis única, seguida de Doxiciclina por vía oral $100 \mathrm{mg} / 12 \mathrm{~h}$ durante 7 días o azitromicina por la posible asociación con clamidia. Cómo alternativa a la ceftriaxona se usa la Espectinomicina 2G IM o Quinolonas.,en la gestación la Doxiciclina puede sustituirse por 
Eritromicina 500mg/6h durante 7 días por vía oral. (Usandizaga, J. \& Pérez, P.; s.f.) (Abad, M.; 2014; p. 24 )

\section{Prevención}

La abstinencia de las relaciones sexuales es el único método absoluto de prevención de la gonorrea. Al igual que en todas las ETS, la pareja estable es la mejor forma de prevenir cualquier ETS. El uso del condón disminuye el riesgo de infección. (Abad, M.; 2014; p. 24 )

Factores de riesgo de las enfermedades de transmisión sexual

Percepción de riesgo

El tener percepción del riesgo significa ser consciente de la probabilidad que uno tiene de adquirir una ETS en una situación determinada, hay factores que hacen que esta percepción disminuya e incluso desaparezca. La tendencia a la disminución de la edad de inicio de las relaciones sexuales es señalada como un riesgo, sobre todo cuando la educación sexual no es la adecuada. El comportamiento es la conducta asumida por la persona respecto a su salud sexual y reproductiva y está muy vinculada con los conocimientos que en este sentido posee. Sin embargo, esto no significa, necesariamente que un buen conocimiento sobre la sexualidad y reproducción se corresponda con comportamientos adecuados en esta esfera de la vida.

- La infravaloración del riesgo personal: Ejemplo la tendencia a atribuirnos menos riesgos a nosotros mismos que a los demás.

- Habituación del riesgo. Se produce al realizar, de forma habitual, comportamientos de riesgo sin que tengan consecuencias negativas, por lo que acaban por no parecer

\footnotetext{
581 Vol. 5, núm. 1, enero 2019, pp. 560-588 Jenny V. Magallanes-Sánchez; Leonela L. Ponce-Lino; Yojana M. Vélez-Valencia; Rosa M. NaviaGonzález; María L. Cedeño-García; María V. Zambrano-Intriago
} 
arriesgado.

- Ilusión de la vulnerabilidad: favorecida por la habituación al riesgo, supone creerse a salvo del peligro de manera infundada.

- Tipo de relación: en las relaciones esporádicas la percepción de riesgo suele ser mayor, pero en las relaciones estables disminuye o desaparece, al sentirse seguros los miembros de la pareja.

- No obstante existen dos situaciones de relación estable donde la sensación de seguridad es en realidad una falsa seguridad.

- En caso de infidelidad no confesada: donde la pareja ha tenido relaciones sexuales con una tercera persona y no se lo comunica a la otra persona por temor a sus consecuencias, con las que se expone a riesgo sin ser ella consciente.

- Monogamia serial: consiste en relaciones monógamas de exclusividad (con una sola persona) que dura un tiempo limitado, al concluir esta se inicia con otra relación también monógama y exclusiva, y así sucesivamente esto hace que los miembros de la pareja se sientan seguros con respecto a las ETS y por lo tanto no ven necesaria la protección, con lo que a medida que pasa el tiempo los riegos se van sumando. (Irahola, 2007)

(Abad, M.; 2014; p. 56-57)

Factores de riesgo culturales

Sexualidad y cultura

La sexualidad humana se encuentra claramente determinada por las apreciaciones que la cultura determina como correctas, permitidas o adecuadas. Esto hace que se abran nuevas

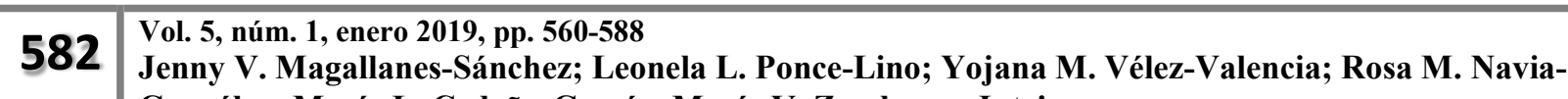
González; María L. Cedeño-García; María V. Zambrano-Intriago
} 
posibilidades para que el estudio y la comprensión de la sexualidad sean más complejos al estar marcada por las variables culturales. Se podría afirmar que la sexualidad es una construcción social ya que no solo es producto de la naturaleza biológica sino también, del entorno cultural y social en el que está inserto el individuo. La sexualidad aparece como una pertenencia de personas sociales integradas dentro del contexto de distintas y diversas culturas sexuales. Somos seres culturales por excelencia y la cultura es algo que se da y se define en la sociedad El punto hasta el cual los hombres y las mujeres pueden controlar los distintos aspectos de sus vidas sexuales (su habilidad de negociar el momento y las condiciones de la relación sexual, así como el uso de preservativo), juega un papel crítico en la determinación de su vulnerabilidad a las infecciones de transmisión sexual

El control que tienen las personas sobre sus propias vidas y alternativas sexuales está, al mismo tiempo, afectado por las normas y valores basados en el género que definen la masculinidad y feminidad. Esas normas y valores de género, culturalmente definidos, evolucionan a través del proceso de socialización que comienza en las primeras etapas de la infancia. Los mismos están determinados y 58 se fortalecen a través de prácticas inadecuadas como el cambio frecuente de pareja, matrimonios a muy temprana edad. Esas prácticas, valores y tradiciones culturales tienen una fuerte influencia en los aspectos visibles de los comportamientos individuales y son determinantes importantes de la vulnerabilidad de las mujeres en relación a las ETS.

El riesgo individual de contraer ETS está determinado por una cantidad de factores sociales y culturales que moldean las percepciones, actitudes y comportamientos relacionados con el género y la sexualidad. 
Las normas de género están arraigadas profundamente en el contexto sociocultural de cada sociedad. Las normas socio-culturales crean las nociones de masculinidad y feminidad que a su vez generan relaciones de poder desequilibradas entre los hombres y las mujeres. Ese desequilibrio de poder, impacta el acceso de las mujeres y de los hombres a los principales recursos, información y relaciones sexuales.

El mismo reduce la autonomía sexual de la mujer y expande la libertad sexual y control del hombre sobre su sexualidad. En culturas donde la virginidad tiene un alto valor, las mujeres jóvenes buscan preservarla al practicar comportamientos sexuales alternativos, como el sexo anal, lo que aumenta su vulnerabilidad al VIH. (Abad, M.; 2014; p. 57-58)

\section{Estigma y tabúes}

El estigma y los tabúes culturales, especialmente los relacionados con el sexo y las actividades sexuales, aumentan la vulnerabilidad al VIH de los hombres y de las mujeres. Los tabúes asociados con el sexo y con el conocimiento actúan como barreras que impiden tanto adquirir información sobre la prevención del VIH, como proveer el tratamiento, atención y apoyo que necesitan aquellos infectados y afectados por el VIH. (Abad, M.; 2014; p. 58)

\section{Religión}

La relación entre religión y sexualidad se ve afectada por la "moral sexual", entendida no tanto como parte de la moral general o común a todas las personas, sino como una parte de la moral religiosa que implica restricciones $\mathrm{u}$ obligaciones al comportamiento sexual humano. Tales comportamientos varían entre unas y otras épocas, así como entre distintas religiones o culturas de forma que, las normas sociales y los estándares de conducta sexuales, suelen estar relacionados con

\footnotetext{
\begin{tabular}{l|l}
584 & Vol. 5, núm. 1, enero 2019, pp. 560-588 \\
Jenny V. Magallanes-Sánchez; Leonela L. Ponce-Lino; Yojana M. Vélez-Valencia; Rosa M. Navia-
\end{tabular} González; María L. Cedeño-García; María V. Zambrano-Intriago
} 
las creencias religiosas.

De acuerdo con esto, la mayor parte de las religiones han visto la necesidad de dirigir la cuestión de un papel "propio" de la sexualidad en las interacciones humanas. En nuestra cultura, la religión católica sanciona el sexo y lo convierte en pecado. Esta categoría de pecado ha generado la doble moral como una práctica continua y cotidiana de sus feligreses, sus sacerdotes, obispos y monjas.

Así se presenta una gran brecha entre "lo que se dice que se hace" "lo que se dice que se debe hacer" y "lo que en realidad se hace" Por otra parte, el control que ejerce la iglesia católica sobre la sexualidad de las mujeres ha afectado, notablemente, a las políticas públicas vinculadas a la salud sexual y reproductiva que se expresa en la prevención de: embarazos y (en general y en adolescentes), enfermedades de transmisión sexual y VIH (SIDA) y otras enfermedades de trasmisión sexual y problemas psicológicos y emocionales derivados de una inexistente o simplemente mala política de salud sexual y reproductiva y de una educación sexual insana.

La religión consagra las directrices éticas de muchos aspectos de nuestra vida diaria y también orienta las creencias y normas que rodean a la sexualidad. La mayoría de las creencias moldeadas por las religiones prohíben el sexo antes del matrimonio, los anticonceptivos incluyendo el uso de condones y la homosexualidad. (Abad, M.; 2014; p. 59-60)

\section{Factor Psicosocial}

Los síntomas recurrentes del herpes genital pueden ser incómodos y llevar a cierta estigmatización social y al sufrimiento psicológico. Esos factores pueden tener un importante efecto en la calidad de vida y las relaciones sexuales. Sin embargo, con el tiempo la mayoría de las 
personas con herpes aprende a sobrellevar la infección. (OMS, 2017)

Se han encontrado escasos artículos que aborden la temática psicosocial en pacientes con herpes genital. Sin embargo, los estudios analizados evidencian un impacto significativo en pacientes que padecen la enfermedad; las secuelas en las dimensiones sociales y psicológicas pueden ser debido a recurrencias, localización de lesiones, ausencia de tratamientos que curen la enfermedad, cronicidad y desconocimiento de las causas de las recurrencias. Los pacientes con herpes genital pueden experimentar sentimientos de depresión, ira, culpa, angustia, autocrítica, disminución del interés sexual y disminución de la autoestima. Otros pacientes expresan pánico y articulan la creencia de que el herpes genital es un castigo por su conducta promiscua. (Maslen, Rodríguez, Gómez, Delfina, \& Moya, 2012)

Sirve de ejemplo referir el trabajo investigativo de (Torres, F.; 2014), quien al respecto menciona que, tras su consulta bibliográfica, pudo notar que básicamente la problemática psicosocial vinculada al contagio del herpes genital se debe a:

- Las consecuencias psicológicas de contraer la enfermedad y el impacto del

- Diagnóstico.

- Factores psicosociales que contribuyen a las recurrencias.

- El revelado de la enfermedad.

- El estigma en las personas con herpes simple genital. (Torres, 2014, p.15)

\section{Conclusiones.}

Las enfermedades de transmisión sexual representan a un grupo de padecimientos infecciosos que como su nombre indica, se adquieren predominantemente por contacto sexual, sin

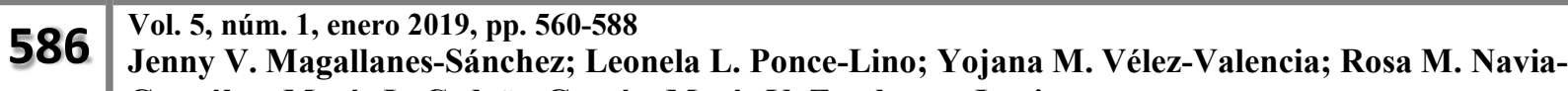
González; María L. Cedeño-García; María V. Zambrano-Intriago
} 
embargo, en algunos casos pueden ser transmitidos por vía no sexual. Su frecuencia ha aumentado, dado que están estrictamente relacionadas con las conductas sexuales de la población. Un grupo de ellas no tienen tratamiento definitivo, y otras están asociadas a la aparición de diferentes cánceres. Su prevención pasa por el cambio de conductas, lo que sólo es posible lograr con educación; que es en lo referente a la práctica del sexo seguro que es el método que permite que las parejas reduzcan sus riesgos en salud sexual, con el uso del condón siempre, trabajo con jóvenes en hábitos de vida saludable, detección y trabajo con poblaciones de riesgo, y la creación de centros especializados para su atención.

Las ETS y sus complicaciones no están distribuidas uniformemente en la población, pues a pesar de que cualquier persona es susceptible de adquirirlas, sólo algunos grupos específicos (sobre todo las mujeres y en general las personas que se encuentran en el medio socioeconómico bajo) son los que se encuentran en riesgo de adquirirlas o transmitirlas con mayor frecuencia; y por ende, es en estos grupos en los que se debe dirigir la mayor parte de las acciones; es de suma importancia la información veraz y comprensible con el fin de incluirlos en los programas nacionales de vigilancia y control.

La educación sexual y la participación en el autocuidado de la salud sexual son procedimientos considerados como altamente efectivos. La abstinencia sexual durante la presencia de lesiones activas o durante los lapsos de tratamiento, tanto para el paciente como para la pareja sexual, es un procedimiento que propicia la curación y evita la transmisión. El uso correcto del condón es una alternativa igualmente confiable para evitar la transmisión de estas infecciones.

\footnotetext{
$\begin{array}{ll}587 & \text { Vol. 5, núm. 1, enero 2019, pp. 560-588 } \\ \text { Jenny V. Magallanes-Sánchez; Leonela L. Ponce-Lino; Yojana M. Vélez-Valencia; Rosa M. Navia- }\end{array}$ González; María L. Cedeño-García; María V. Zambrano-Intriago
} 


\section{Bibliografía.}

Abad Camacho, M. R. (2014). Factores de riesgo culturales y enfermedades de transmisión sexual en mujeres en edad fértil atendidas en en el Centro de Salud $N^{\circ} 2$ Dr. Hugo Guillermo González de Loja. Tesis de Pre-Grado, Centro de Salud № 2 Dr. Hugo Guillermo González de Loja, Loja - $\quad$ Ecuador. Obtenido de http://dspace.unl.edu.ec/jspui/handle/123456789/12435

Berdasquera Corcho, D., Fariñas Reinoso, A., \& Ramos Valle, I. (Marzo-Abril de 2001). Las enfermedades de transmisión sexual en embarazadas. Un problema de salud a nivel mundial. Revista Cubana de Medicina General Integral, 17(2). Obtenido de http://scielo.sld.cu/scielo.php?script=sci_arttext\&pid=S0864-21252001000200013

Delgado, K., Caicedo, L., Manrique, M., \& Cañón, M. (Octubre-Diciembre de 2014). Manejo de herpes genital en pacientes inmunocompetente. Revista Médica Sanitas, 17(4), 202-211. Obtenido

https://www.researchgate.net/profile/Maria_Manrique3/publication/270272586_Manejo_de_ herpes_genital_en_pacientes_inmunocompetentes/links/54fe16b60cf2eaf210b22 cdb/Manejo -de-herpes-genital-en-pacientes-inmunocompetentes.pdf

Giménez, S. (10 de 04 de 2014). medicina21.com. (S. Ediciones Farmavet, Editor) Obtenido de medicina21.com: https://www.medicina21.com/Articulos/V75/Herpes-genital-La-infeccionpor-el-virus-del-herpes-simple.html

Hernández Cortina, A. (2008). Infección por herpes simple genital. Revisión global. Revista Habanera de Ciencias Médicas, 7(4). Obtenido de http://scielo.sld.cu/scielo.php?script=sci_arttext\&pid=S1729-519X2008000400019

Maslen, M., Rodríguez, K., Gómez, I., Delfina, A., \& Moya, N. (2012). Referentes teóricos sobre algunos tipos de herpes. Revista de Información Científica, 73(1). Obtenido de http://www.revinfcientifica.sld.cu/index.php/ric/article/view/674/1634

Mayo Clinic. (03 de 10 de 2017). mayoclinic.org. Obtenido de mayoclinic.org: https://www.mayoclinic.org/es-es/diseases-conditions/genital-herpes/symptoms-causes/syc20356161

OMS. (2017). Organización Mundial de la Salud. Ginebra - Suiza: WHO. Obtenido de Organización Mundial de la Salud: https://www.who.int/es/news-room/factsheets/detail/herpes-simplex-virus

Torres, F. (2014). Prevalencia de herpes I y II y sus factores de riesgo en pacientes de 20 a 30 años de edad que acuden al distrito 07D02 Machala-Salud durante el año 2013. Tesis, Machala El Oro - Ecuador. Obtenido de http://repositorio.utmachala.edu.ec/handle/48000/853 